\title{
Reconstrucción de labio con Técnica de Karapandzic
}

\section{Lip reconstruction with Karapandzic’s technique}

\author{
Matos da Fonseca, A.*, Gómez García, F.**
}

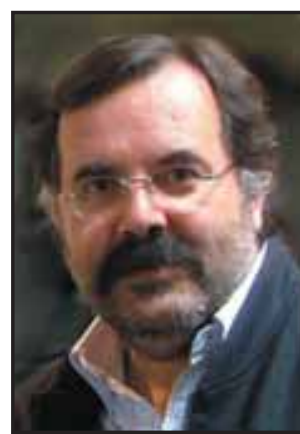

Matos da Fonseca, $\mathbf{A}$.
Resumen

El Carcinoma Epidermoide es el más frecuente entre los tumores malignos de los labios. La región de los labios representa una zona anatómica de interés debido a que tiene una frecuencia importante de patología tumoral y a que involucra el esfínter natural de la cavidad bucal. Su reconstrucción es un desafío para el cirujano, que debe tratar de lograr un buen resultado tanto funcional como estético.

Debido a esto, se han descrito numerosas técnicas para la reconstrucción de esta zona. Nosotros seguimos una técnica basada en la preservación anatómica de los pedículos vásculonerviosos faciales que mantiene la irrigación y la funcionalidad futura del labio. Mostramos en este trabajo la aplicación clínica de dicha técnica.
Palabras clave Carcinoma epidermoide. Labio. Técnica de Karapandzic.

Código numérico 2240-15831

\begin{tabular}{|ll} 
Key words & $\begin{array}{l}\text { Epidermoid Carcinoma. Lips. Karapand- } \\
\text { zic Technique. }\end{array}$ \\
Numeral Code & $2240-15831$
\end{tabular}

Epidermoid Carcinoma is the most frecuent malignant tumor of the lips.

The lips represent an important area of interest because of the frequency of tumoral pathology and because it involves the natural sphincter of the oral cavity.

Its reconstruction is a challenge for the surgeon, trying to achieve good results, not only functional but also aesthetic. Many techniques have been described for their reconstruction. We follow one based on the anatomical preservation of the facial vasculonervous pediculus that keeps the irrigation and the future functioning of the lip.

In this work, we present its clinical application.

\footnotetext{
* Cirujano Máxilo-Facial. Director Clínca da Face.

* Cirujano Plástico.

Clínica da Face. Lisboa. Portugal.
} 


\section{Introducción}

De entre los tumores malignos de los labios, el más frecuente es el Carcinoma Epidermoide. Se trata de un tumor agresivo, invasor, que puede dar metástasis si no es tratado precoz y radicalmente. Es más frecuente en el labio inferior. Su epidemiología nos habla de que este tumor es 10 veces más frecuente en hombres que en mujeres.

En relación a su patogénesis, el carcinoma epidermoide presenta varias características: Aumenta en los individuos de piel clara, sobre todo con fototipos 1 y 2 ; crece en pacientes expuestos a radiaciones ultravioletas $\mathrm{y}$, sobre todo, a rayos $\mathrm{x}$; los cambios inflamatorios $\mathrm{y}$ enfermedades crónicas están íntimamente relacionados con el desarrollo de este tipo de cáncer, preferentemente las lesiones preneoplásicas, cicatrices por lupus, por quemaduras y cicatrices a tensión; otra causa relacionada con el carcinoma epidermoide son las infecciones virales con predominio del herpes virus; finalmente, los pacientes inmunodeprimidos tienen mayores probabilidades de desarrollar este tipo de tumor.

Histológicamente es un tumor que se desarrolla a partir de las células del estrato espinoso (queratinocitos). Encontramos en la capa dérmica un aumento del infiltrado linfocitario así como también una vascularización elevada. Su particularidad más característica, es la presencia de globos de queratinocitos y perlas córneas.

Desde un punto de vista clínico, existen básicamente dos variedades:

a. Carcinoma espinocelular intradérmico: también llamado carcinoma in situ, relacionado con lesiones preexistentes como inflamaciones crónicas, lesiones arsenicales, quemaduras térmicas, enfermedad de Bowen, etc. que tiene mejor pronóstico.

b. Carcinoma espinocelular invasor: que es de crecimiento rápido e ilimitado. Si no se trata puede provocar la muerte por metástasis. Este tumor tiene un acelerado crecimiento en piel sana y también está relacionado con la eritroplasia de Queyrat. El 20 al 40\% de estas eritroplasias desarrollan carcinoma epidermoide.

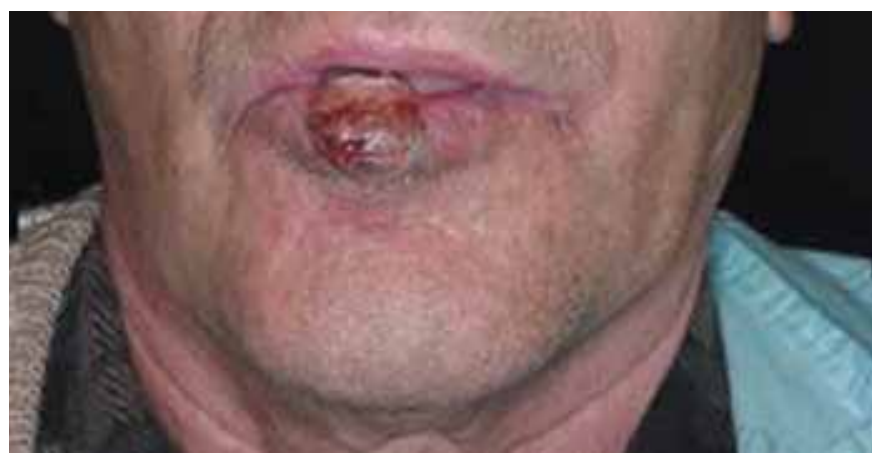

Figs. 1 y 2. Aspecto del paciente. Detalle de la lesión.
La superficie puede sangrar, tener una costra y los márgenes de la úlcera pueden elevarse y es duro al tacto.

\section{Caso clínico}

Varón de 64 años que consulta por lesión vegetante de labio inferior de 6 meses de evolución. La lesión fue creciendo en forma lenta y paulatina hasta llegar a ocupar el $40 \%$ del labio inferior, con medidas de $2 \mathrm{x}$ $2 \mathrm{~cm}$. de diámetro. No se palpaban adenopatías regionales (Fig. 1 y 2 ).

Se realizó una biopsia insicional y, posteriormente, se envío a Anatomía Patológica que lo diagnosticó como Carcinoma Espinocelular (Fig. 3-5).

Según la nomenclatura TNM fue etiquetado como T2, N0, M0.

Se decidió extirpación de la lesión bajo anestesia general y reconstrucción con técnica de Karapandzic. También se realizó vaciamiento ganglionar cervical suprahomohioideo.

\section{Técnica quirúrgica}

Basándonos en la descripción de Miodrag Karapandzic (1), comenzamos por la marcación del área a extirpar con los respectivos colgajos (Fig. 6).

Se realiza la extirpación de la masa tumoral y se realiza biopsia por congelación intraoperatoria (Técnica de Mohs), que informa de que los bordes están libres de afectación.

Se procede al tallado de los colgajos miocutáneos en forma delicada.

Se disecciona el músculo orbicularis oris con tijeras delicadas de Iris hasta encontrar las ramas arteriales y venosas (labiales superior e inferior) ramas de la arteria y vena faciales, identificándolas y preservándolas.

Se buscan las ramas nerviosas, identificando las mismas y preservando todos los ramos bucales como faciales. Este método permite el avance de la piel y del músculo dejando intacta la mucosa subyacente. Además, hay que tener en cuenta que los labios son estructuras móviles y sensoriales y la reconstrucción

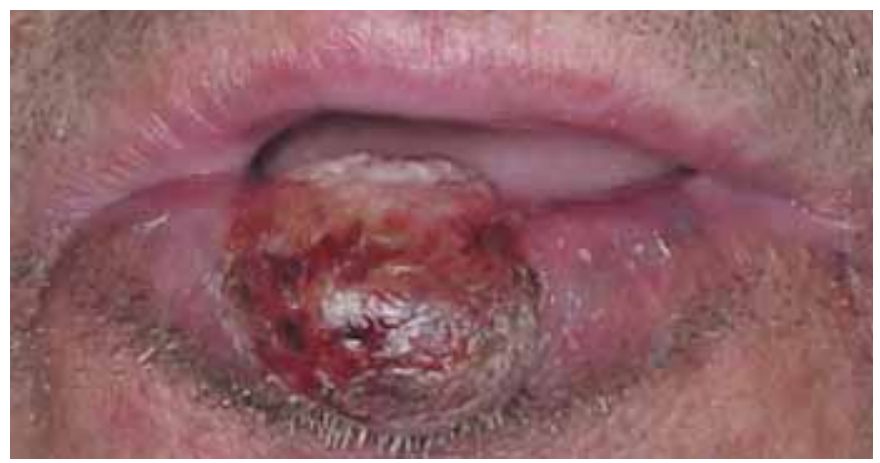




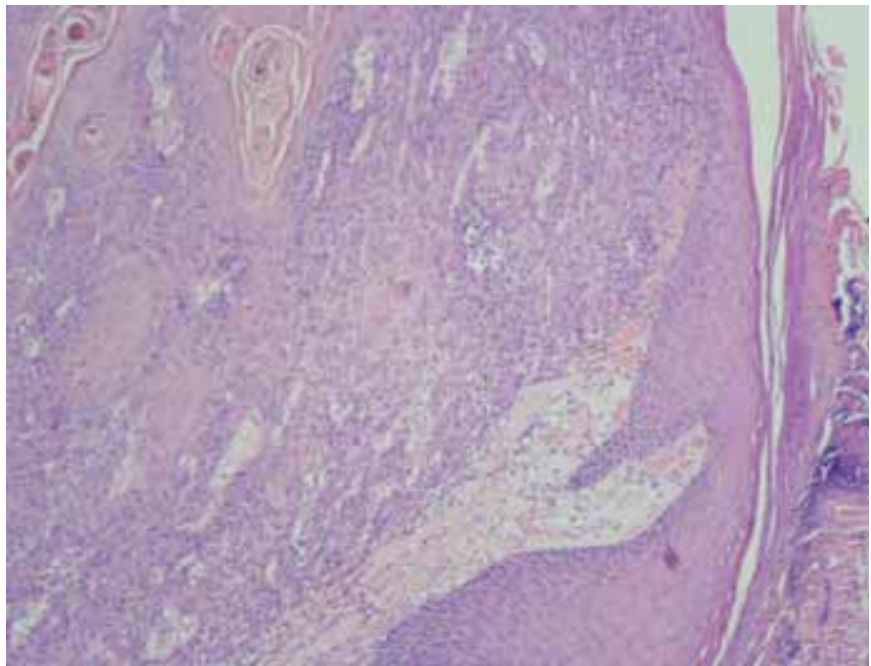

Fig. 3. Aspecto de la transición mucosa normal/mucosa neoplásica teñida con hematoxilina-eosina a $40 \mathrm{X}$.

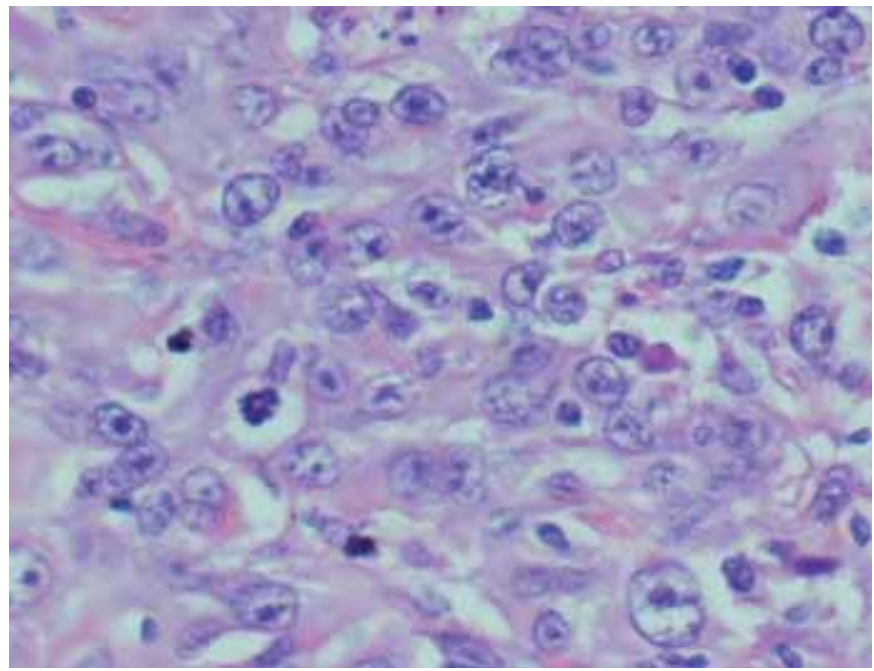

Fig. 5. Células neoplásicas con núcleos grandes, inversión de la relación núcleo-citoplasma, nucleolos evidentes y mitosis atípicas a 400X.

de los mismos tiene que respetar este principio. Estos colgajos son remarcadamente móviles y pueden ser rotados hacia el defecto sin estrangulación de los vasos sanguíneos.

Se realiza hemostasia cuidadosa con electrobisturí bipolar y se procede al cierre del tejido celular subcutáneo con puntos sueltos de Vicryl @ 4.0 dejando el nudo hacia dentro. La mucosa labial se sutura con Vicryl Rapid® 4.0. El cierre de piel se hace con puntos sueltos de mononaylon 6.0. No dejamos drenajes. Finalmente cubrimos todo con adhesivos especiales que permiten al paciente mojar la zona (Op-site $\left.{ }^{\circledR}\right)$.

El procedimiento fu bien tolerado durante el postoperatorio (Fig 7).

\section{Resultados}

Se retiraron los puntos a los 7 días de la intervención. No se observó sufrimiento de los colgajos, hematomas ni dehiscencias de la zona operatoria.

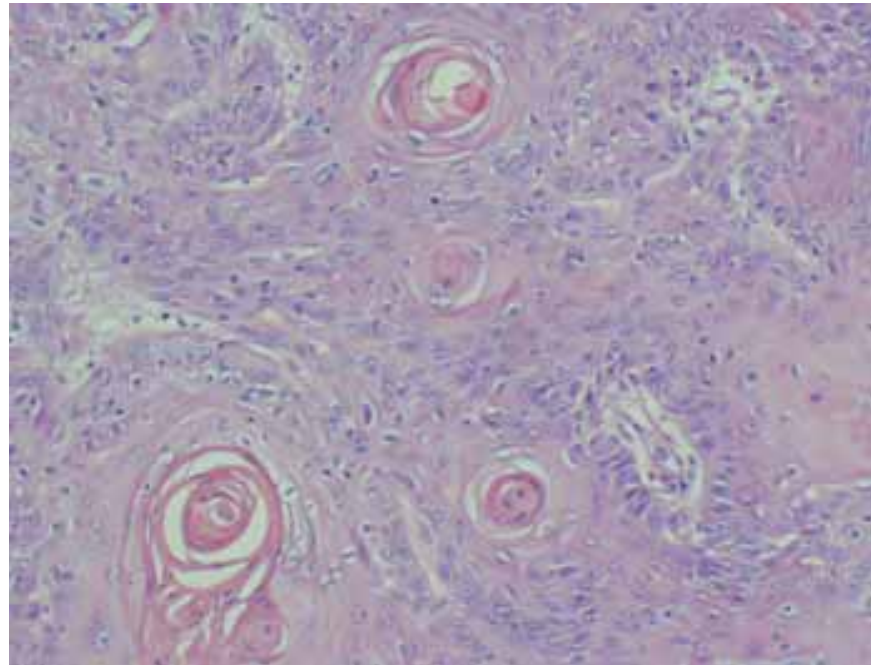

Fig. 4. Aspecto típico de "perlas de queratina" con infiltrado linfocitario a 100X.

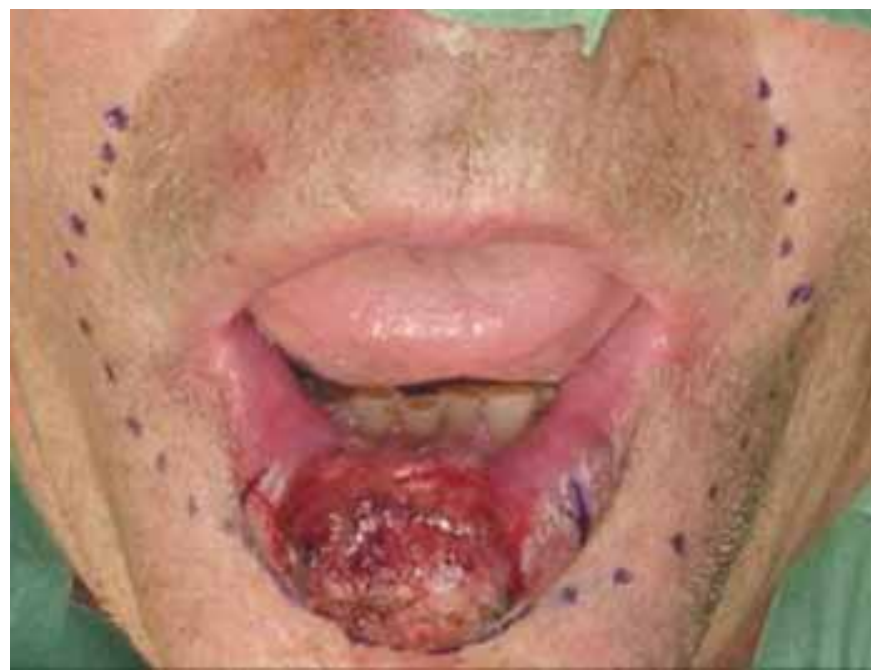

Fig. 6. Marcaje de los futuros colgajos con el paciente intubado por vía naso-traqueal.

Se preservó totalmente la sensibilidad de la zona operatoria. Se obtuvo un resultado satisfactorio tanto desde el punto de vista funcional como estético.

El seguimiento postoperatorio ha sido de 5 años, sin que hasta la fecha haya habido aparición de metástasis a distancia. En la actualidad el paciente está libre de toda lesión (Fig. 8, 9).

\section{Discusión}

Como describen diferentes autores (2), no existe un método ideal para la reconstrucción de los labios. Si la lesión ocupa hasta 1/3 del borde del labio, el cierre puede ser realizado en forma directa, o se puede recurrir a plastía en W. Cuando la lesión ocupa más del $35 \%$ del labio, se precisa para el cierre reconstrucción con colgajos $(3,4)$. La mayoría de ellos utilizan piel de las zonas próximas como son el labio no afectado 


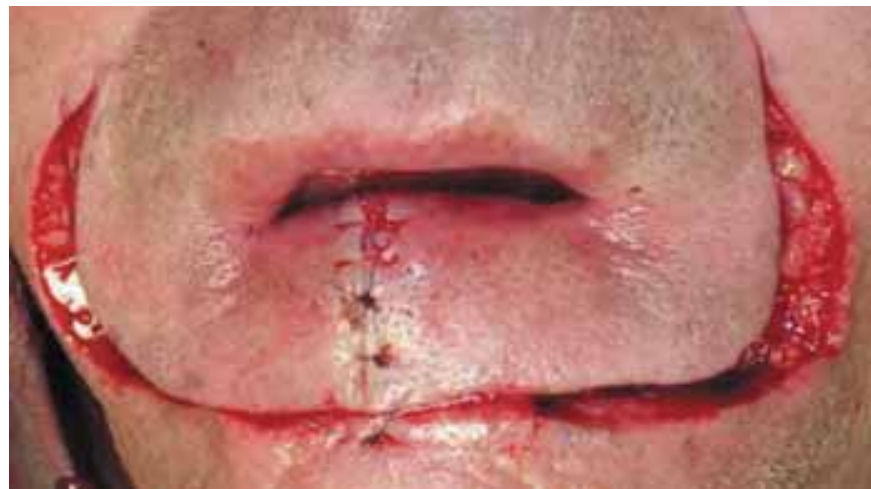

Fig. 7. Tallado de los colgajos tras resecar la lesión y movilizar los mismos con cierre y formación del nuevo labio.

tipo Abbe (5), de la mejilla tipo Guillies o Estlander (4), del mentón tipo Bernard, etc.

La técnica elegida por nosotros, proporciona a nuestro juicio para lesiones importantes la ventaja de que se realiza en un solo acto quirúrgico, que una vez aprendida es de rápida realización y que preserva una importante red vásculonerviosa (6- 9), permitiendo una amplia seguridad futura y manteniendo una buena movilidad y sensibilidad (9).

Los mejores resultados con la técnica de Karapandzic, se obtienen cuando la lesión se encuentra en el centro de los labios. Cuando están en los ángulos, los resultados no son tan satisfactorios.

El principal inconveniente descrito para esta técnica es la microstomía $(10,11)$. Existe un porcentaje que oscila entre el 12 al 15\% de reintervenciones para mejorar la misma, lo que se realiza mediante comisuroplastia.

\section{Conclusiones}

La reconstrucción de labio mediante la técnica de Karapandzic es un procedimiento alternativo para grandes lesiones mayores del $35 \%$, sobre todo del labio inferior, debido a que se realiza en un solo pro- cedimiento, es rápida y segura ya que mantiene un pedículo vásculo-nervioso y que proporciona resultados excelentes tanto desde el punto de vista funcional como estético. Su mayor inconveniente es la producción de microstomía, que se produce en etapas tempranas, mejorando gradualmente con el tiempo.

\section{Dirección del autor}

\author{
Dr. Antonio Matos da Fonseca \\ Clínica Da Face. \\ Rua Tomas da Fonseca, Torre F - 1 andar \\ 1600-209- Lisboa-Portugal \\ e-mail: amf@clinicadaface.com \\ fgomez@clinicadaface.com
}

\section{Bibliografía}

1. Karapandzic M. "Reconstruction of lip defects by arterial flaps". Br J Plast Surg. 1974; 27(1):93.

2. Jabaley ME, Orcutt TW Clement RL. "Applications of the Karapandzic principle of lip reconstruction after excision of lip cancer". Am J Surg. 1976; 132(4):529.

3. Nzakamwita M, Linker M, Gitani J, Piert R. "Repair of tissue loss of the lips". Acta Stomatol Belg. 1995; 92(4): 159.

4. Abulafia AJ, Edilberto L, Fernanda V. "Reconstruction of the lower lip and chin with local flaps". Plast Reconstr Surg. 1996; 97(4):847.

5. Calhoun KH. "Reconstruction of small- and medium- sized defects of the lower lip". Am J Otolaryngology. 1992; 13(1):16.

$6 \quad$ Kroll SS. "Staged sequential flap reconstruction for large lower lip defects". Plast Reconstr Surg. 199; 88(4):620; discussion 626.

7. Jabaley ME, Clement RL; Orcutt TW. "Myocutaneus flaps in lip reconstruction. Applications of the Karapandzic principle". Plast Reconstr Surg. 1977; 59(5):680.

8. Hills RJ. "Innervated musculocutaneous lip flap (Karapandzic technique)”. Australas J Dermatol. 1998; 39(3):190.

9. Clairmont AA. "Versatile Karapandzic lip reconstruction". Arch Otolaryngol. 1977; 103(11):631.

10. Smith PG, Muntz HR, Thawley SE. "Local myocutaneous advancement flaps. Alternatives to cross-lip and distant flaps in the reconstruction of ablative lip defects". Arch Otolaryngol. 1982; 108(11):714

11. Rashid M, Hanif MS; Illahi I, Aslam R, Hameed S, Masood T.: "Reconstruction of lip defects with the Karapandzic technique". J Coll Physicians Surg Pak. 2003; 13(4):219.
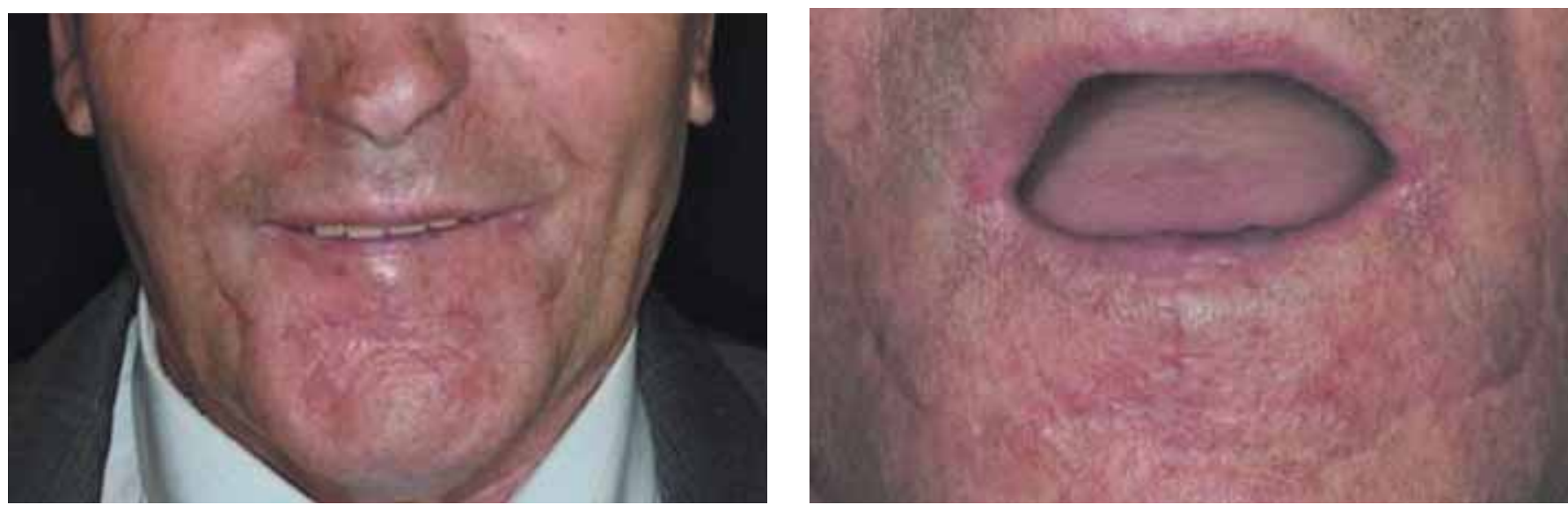

Figs. 8 y 9. Aspecto postoperatorio a los 6 meses de la cirugía. El paciente sonriendo y con la boca abierta. 


\title{
Reconstrução do lábio com a Técnica de Karapandzic
}

\author{
Matos da Fonseca, A.*, Gómez García, F.**
}

\section{Resumo}

O Carcinoma Epidermóide é o mais frequente entre os tumores malignos dos lábios. A região labial representa uma zona anatómica de elevado interesse devido à frequência de patologia tumoral envolvendo aquele que é o esfíncter natural da cavidade bucal. A sua reconstrução é um desafio para o cirurgião, que deve tratar de conseguir um bom resultado, tanto funcional como estético.

Por isso se descreveram numerosas técnicas para a reconstrução desta zona. Neste caso seguimos uma técnica baseada na preservação anatómica dos pedículos vasculo-nervosos faciais que mantêm a futura irrigação e funcionalidade do lábio. Apresentamos neste trabalho a aplicação clínica desta técnica.

\section{Introdução}

De entre os tumores malignos dos lábios, o mais frequente é o Carcinoma Epidermóide. Trata-se de um tumor agressivo, invasor, que pode metastisar se não for tratado precocemente e radicalmente. É mais frequente no lábio inferior. A sua epidemiologia diz-nos que este tumor é 10 vezes mais frequente nos homens que nas mulheres.

Em relação à sua patogénese, o carcinoma epidermóide apresenta várias características: é mais frequente nos indivíduos de pele clara, sobre tudo com fototipos 1 e 2 ; a frequência aumenta em doentes expostos a radiações ultravioletas e, sobre tudo, a raios X; as alterações inflamatórias e as doenças crónicas estão intimamente relacionados com o desenvolvimento deste tipo de cancro, particularmente as lesões pré-neoplásicas, cicatrizes de lúpus e queimaduras e cicatrizes a tensão; outra causa, relacionada com o carcinoma epidermóide, é a prévia infecção viral com predomínio para o herpes vírus; finalmente, os pacientes imunodeprimidos têm maiores probabilidades de desenvolver este tipo de tumor.

Histologicamente é um tumor que se desenvolve a partir das células do estrato espinhoso (queratinocitos). Encontramos na camada dérmica um aumento do infiltrado linfocitário assim como uma vascularização elevada. A sua particularidade mais característica, é a presença de esferas de queratinocitos e pérolas córneas.

Do ponto de vista clínico, existem basicamente 2 variedades:

A - O carcinoma espinocelular intra-dérmico: também chamado carcinoma "in situ", relacionado com lesões pré-existentes como inflamações crónicas, lesões arsenicais, queimaduras térmicas, doença de Bowen, etc., e que tem melhor prognóstico.

$\mathrm{B}$ - O carcinoma espinocelular invasivo: que é de crescimento rápido e ilimitado. Si não for tratado poderá provocar a morte por metástases. Este tumor tem um acelerado crescimento na pele sã e também está relacionado com a eritroplasia de Queerat. 20 a 40\% destas eritroplasias desenvolvem um carcinoma epidermóide.

A superfície poderá sangrar, ter uma crosta e as margens da úlcera elevam-se e são duras ao tacto.

\section{Caso clínico}

Homem de 64 anos que nos consulta por apresentar uma lesão vegetante do lábio inferior com 6 meses de evolução. A lesão cresceu de forma lenta e demorada até chegar a ocupar $40 \%$ da superfície do vermelhão do lábio inferior, com medidas de $2 \times 2 \mathrm{~cm}$ de diâmetro. Não se palpavam adenopatias regionais (Fig. 1 e 2).

Realizou-se uma biopsia incisional que diagnosticou um Carcinoma Espinocelular (Fig. 3-5).
Segundo a nomenclatura TNM foi qualificado como T2, N0, M0. Decidimos proceder à extirpação da lesão sob anestesia geral e reconstrução com a técnica de Karapandzic. Também se realizou esvaziamento ganglionar cervical supra-homo-hioideu.

\section{Técnica cirúrgica}

Baseados na descrição de Miodrag Karapandzic (1), começámos pela marcação da área a extirpar, com os respectivos retalhos (Fig. 6).

Realizou-se a excisão da massa tumoral e biopsia por congelação intra-operatória (Técnica de Mohs), que informou que a periferia da peça operatória não se encontrava afectada.

Procedeu-se à dissecção dos retalhos miocutâneos de forma delicada.

Dissecou-se o músculo orbicularis oris com tesouras delicadas, de íris, até encontrar os ramos arteriais e venosos (labiais superior e inferior) ramos da artéria e veia faciais, identificando-as e preservando-as.

Procurámos identificar os ramos nervosos, identificando-os e preservando todos os ramos bucais e faciais.

Este método permite o avanço da pele e do músculo deixando intacta a mucosa subjacente. Além disso, à que ter em conta que os lábios são estruturas móveis e sensoriais e a reconstrução tem que respeitar este princípio. Estes retalhos são marcadamente móveis e podem ser mobilizados até ao defeito sem estrangulamento dos vasos sanguíneos.

Realizou-se a hemostase cuidadosa com electro-bisturi bipolar e procedeu-se ao encerramento do tecido celular subcutâneo com pontos separados de Vicryl @ 4.0 deixando os nós virados para dentro. A mucosa labial suturou-se com Vicryl Rapid® 4.0. A sutura da pele fez-se com pontos separados de mononylon ${ }^{\circledR}$ 6.0. Não deixámos drenagens. Finalmente cobrimos toda a superfície com adesivos especiais que permitissem ao doente molhar a zona (Op-site $\left.{ }^{\circledR}\right)$.

O procedimento foi bem tolerado durante o pós-operatório (Fig. 7).

\section{Resultados}

Removeram-se os pontos 7 dias após a intervenção. Não se observou sofrimento dos retalhos, hematomas nem deiscências na zona operatória.

Preservou-se totalmente a sensibilidade da zona operatória. Obteve-se um resultado satisfatório, tanto desde o ponto de vista funcional como estético.

O seguimento pós-operatório foi de 5 anos, sem que, até à data, existam sinais de recidiva local ou de metástases à distância. Na actualidade o doente encontra-se livre de qualquer lesão (Fig. 8, 9).

\section{Discussão}

Como descreveram diferentes autores (2), não existe um método ideal para a reconstrução dos lábios. Se a lesão ocupa até $1 / 3$ do bordo do lábio, o encerramento pode ser realizado de forma directa, ou pode-se recorrer a plastia em W. Quando a lesão ocupa mais de $35 \%$ do lábio, necessita-se, para o seu encerramento, de usar retalhos $(3,4)$. A maioria dos autores utiliza pele das zonas próximas, seja é o outro lábio, não afectado, tipo Abbe (5), a bochecha, tipo Gillies ou Estlander (4), o mento, tipo Bernard, etc.

A técnica por nós escolhida, para lesões importantes, tem a vantagem de se realizar num único acto cirúrgico, que uma vez aprendida é de rápida execução e preserva uma importante rede vasculo-nervosa (6- 9) permitindo maior segurança futura e a manutenção de uma boa mobilidade e sensibilidade do lábio (9). 
Os melhores resultados com a técnica de Karapandzic, obtêm-se quando a lesão se encontra na região mediana dos lábios. Quando afectam os ângulos, os resultados não são tão satisfatórios.

O principal inconveniente descrito para esta técnica é a microstomia $(10,11)$. Existe uma percentagem que oscila entre os 12 e os $15 \%$ de re-intervenções para melhorar a microstomia, realizando-se, então, uma comissuroplastia.

\section{Conclusões}

A reconstrução de lábio utilizando a técnica de Karapandzic é um procedimento alternativo para as grandes lesões, maiores que $35 \%$, sobre tudo do lábio inferior, já que se realiza num só procedimento, é rápida e segura tendo em conta que mantém um pedículo vasculonervoso e proporciona resultados excelentes tanto do ponto de vista funcional como estético. O seu maior inconveniente é a produção de microstomia, que se produz nas etapas precoces, melhorando gradualmente com o tempo. 